\title{
Desafios ao estudo da contaminação humana e ambiental por agrotóxicos
}

\author{
Challenges in the study of human \\ and environmental contamination by pesticides
}

Frederi co Peres 1

Jeffers on José Oliveira-Silva 1

Hen rique Vicente Della-Rosa 2

Sérgio Roberto de $\mathrm{Lu}_{\mathrm{cca}}{ }^{3}$

\footnotetext{
1 Cen tro de Estu dos da Saúde do Trabalhadr

e Ecologia Humana, Es cola Naci onal de Saúde Pública, Fiocruz. Rua Leopo 1 do Bulhões 1480, Manguinhos, 21041-210, Rio de Ja neiro RJ. fperes@fiocruz.br 2 Faculdade de Ciências Fa rmacêuticas, USP.

3 Área da Saúde Ocupacional, Departamento de Medicina Preven tiva e Social da Faculdade de Ciências Médicas, Unicamp.
}

Abstract The impact of pesticides' use on human health is a probl em that has deserved attention of the scientific community around world, especially in the devel oping countries. Its evaluation demands the knowled ge and the visualization of the relative importance/magnitude of all the contamination routes. Innumerable factors, such as methodological difficulties related with the evaluation of occupational exposition to pesticides, the high taxes of cases subnotification, the non-consideration of the influence of social and economic determinants in risks assessment approaches and the influence of chemical industry pressu re in the pesticides' consumption profile in $B$ razilian agricultural areas. The present work discusses the importance of these facto rs as determinants of rural workers health status, by analyzing the results of field researches performed in agricultural regions of Rio de Janeiro State.

Key words Human contamination by pesticides, Risk assessment, Worker's health
Resumo O impacto do uso de agrotóxicos sobre a saúde humana é um probl ema que tem merecido atenção da co munidade científica em todo o mundo, sob retudo nos países em desenvolvimento. Sua avaliação demanda o conhecimento e a visualização da importância/magnitude relativa de cada uma das vias de contaminação. Inúmeros fatores, tais como as dificuldades metodológicas relacionadas com o monito ra men to da exposição ocupa cional aos agrotóxicos, as el evadas taxas de subnotificação de casos, a não-consideração de determinantes sociais e econômicos na avaliação de riscos relacionados a estes agentes químicos e a influência da pressão da indústria produto ra de agrotóxicos no perfil do consumo destes agentes no meio rural brasileiro. No presente trabalho discute-se a importância destes fatores como determinantes da situação de saúde do homem do campo, a partir dos resultados de pesquisas de campo realizadas em regiões agrícolas do Estado do Rio de Janeiro.

Palavras-chave Contaminação humana por agrotóxicos, Avaliação de riscos, Saúde do tra balhador 


\section{Introdução}

Os agrotóxicos são agen tes constituídos por uma gran de varied ade de com pos tos químicos (principalmente) ou biológicos, desenvolvidos para matar, ex terminar, comb a ter, repelir a vida (além de controlarem processos específicos, como os reguladores do crescimento). Norm a lmente, têm ação sobre a consti tuição física e a saúde do ser humano, além de se apresentarem como importan tes contaminantes ambi entais e das populações de animais a estes ambientes rel aci on adas (Anvisa, 2002).

Os agrotóxicos aparecem no Brasil, na década de 1960-1970, como a solução científica para o con trole das pragas que ati n giam lavo $u$ ras e rebanhos (Peres et al., 2003). Tal visão, refor ç ada pela forte e cre s cen te atuação da indústria química no país, passou a legitimar o uso indiscriminado de agrotóxicos no meio ru ral e, ao mesmo tem po em que este saber se fazia dominantee dominador, não eram oferecidas alternativas à grande massa de trabalhadores que, ano a ano, se expunha cada vez mais aos efei tos nocivos destas substâncias.

O Ministério da Saúde estima que mais de 400.000 pessoas são contaminadas anualmen te por agrotóxicos, somente no país. Tais estimativas levam em conta o número de casos noti fi c ados no país (aproximadamente 8.000 em 2002 Sinitox, 2003) multiplicados por 50 , fator de correção usado pelo Mnistério da Saúde para dimen sionaro número de casos não-notificados. Em todo o planet a, o número de pessoas expo stas a estes agen tes ch ega a casa dos milhões (25 milhões som en te nos países em de s envo lvi mento - Jeyara tnam, 1990; Levi en \& Doull, 1993).

A saúde humana pode ser afetada pelos agrotóxicos diretamente, através do contato com estas substâncias - ou através do contato com produtos e/ou ambien tes por estes contaminados - e, indiretamente, através da contaminação da biota de áreas próximas a plantações agrícolas, que acaba por desequilibrar os ecossistemas locais, tra zendo uma série de injúrias aos habitantes dessas regiões. As formas de exposição respon sáveis pelos impactos destes agentes sobre o hom em são razoavelmente conhecidas. Os processos através dos quais as populações humanas estão expostas, entretanto, constitu em-se, ainda hoje, verd adeiros mistérios, dada a multiplicidade de fatores que estão envo lvidos.

Os riscos da contaminação, mais que enti$\mathrm{d}$ ades físicas indepen den tes, estão intimamente relacionados às formas através das quais estas populações se relacionam com os peri gos existentes, processos estes fortemen te enviesados por determinantes de ordens social, cultural e econômica. O conhecimen to destes determinantes é essencial ao entendimen to do problema, responsável pela morte de milhares de pess oas - e o adoecim en to de milhões - em todo o mundo, razão pela qual o objeto do estu do da contaminação humana e ambiental por agrotóxicos é ex trem a m en te com plexo.

Existe uma série de complicadores, de ordem metodológica, analítica e estrutural, que contribu em para a imprecisão dos dados disponíveis sobre intoxicações, em todo o mundo, acarretando na consolidação de verdadeiras ba rrei ras às iniciativas de intervenção e ao processo de formulação e implem entação de políticas públicas específicas.

No presente trabalho serão discutidos alguns dos principais determinantes da contaminação humana e ambiental por agrotóxicos e os principais desafios a serem su perados pelos profissionais que atuam na avaliação e con trole dos problemas associados a esta contaminação/exposição. Serão apresentados alguns dos complicadores, de ordem estrutu ral e prática, e de que forma esses fatores podem influ enciar o entendimento dos processos através dos quais as populações humanas tornam-se, a cada ano, $\mathrm{c}$ ada vez mais vuln erá veis a estes agentes. As informações apre sen tadas serão con textualizadas com dados de trabalhos anteriores - já publicados - realizados por uma equipe de pesqui$s$ adores do Cen tro de Estu dos da Saúde do Trabalhador e Ecologia Humana (Cesteh/Ensp Fioc ruz) em regiões rurais do Estado do Rio de Janeiro (Moreira et al., 2002; Oliveira-Silva, 1994; Ol ivei ra - Si lva et al. , 2000; 2001; 2003; Peres, 1999; 2003a; Peres et al., 2001; 2004).

\section{O desafio do moni toramento da exposição humana a agrotóxicos: uma breve discussão}

O monitoram en to da ex posição humana é um processo que demanda significa tivos rec u rsos humanos e materiais - e tem por obj etivo primordial iden tificar precocemente o potencial de agravo à saúde de determinado agente. Assim, através de diversos processos analíti cos e de diagnóstico, é possível iden tificar situações, indivíduos ou gru pos com maior probabilidade de desenvolver processos patológi cos deri- 
vados da exposição a um determinado agente; ademais, através destes mesmos processos di a gnósticos, é possível iden tificar determinadas alterações patológicas em estágio inicial de desenvo lvim en to.

O mon itoramento da exposição humana a agentes tóxicos contribui significativamen te para a redução do número de pessoas a serem avaliadas clinicamente, impede o estabelecimen to de qu ad ros indivi duais de intoxicação a través do afastamen to do trabalhador da fon te de contaminação - e atenua a gravidade deste quadro, nos casos em que os indivíduos já se en con tram intoxicados. Adicionalmente, facilita o processo de tratamento dos indivíduos intoxicados, através da indicação terapêutica mais adequ ada ao agente (quím i cooubiológico) encon trado.

Os agrotóxicos repres entam um gru po heterog ê n eo de com po stos que podem va riar tanto na sua estrutura química quan to nos seus diferen tes mecanismos tóxicos de ação (Larini, 1999). Por essa razão, torna-se muito difícil o desenvolvimen to de um método único e universal capaz de indicar a dose interna, ou mesmo o efei to biológi co da exposição, a todo e qualqu er agen te utilizado com o propósi to de controlar e/ou eliminar pragas.

Assim, d iversos métodos vêm sen do utilizados, ao lon go dos últimos 50 anos, para avaliar a exposição humana a agentes químicos como os agrotóxicos. Os principais são os métodos de diagnóstico através de indicadores de dose interna e de indicadores de efei to.

Os métodos diagnósti cos que se baseiam na utilização de indicadores de dose interna determinam a con centração da substância química e/ou metabólito(s) presentes em matrizes biológicas, tais como, sangue, urina ou tecidos. As técnicas mais difundidas de quantificação destes indicadores são a crom a tografia em fase gasosa ou em fase líquida de alta performance com o auxílio de vários detectores (Mukherjee \& Gopal, 1996; Bi ziuk et al., 1996). Estas técnicas apres entam alta sensibilidade, produ zem resultados exatos e possibilitam a avaliação da relação entre o agrotóxico em sua forma original e seus (sub) produtos - fato este que possibilita estudar o processo metabólico que esta substância sof re no or ganismo.

As análises cromatográficas geralmente requerem o uso de equipamen tos caros, etapas preliminares de ex tração, mas têm a vantagem de poderem ser utilizadas na determinação de todos os tipos de agrotóxicos e na determina- ção quali e qu a n ti t a tiva de diversas substâncias, simultaneamente em uma mesma amostra.

Outras técnicas analíticas tais como a espectrofo tom etria de absorção atômica, a voltametria e os imunoensaios podem também ser utilizadas com o obj etivo de determinar a con centração de um agente tóxico no organismo (Garrido et al., 2003; Turdean et al., 2002; Sampedro et al., 1998). Todas elas possuem características e limitações próprias, mas a principal limitação relacionada ao uso destas metodologias em um país como o Brasil é de ordem econômica.

Já os indicadores de efei to são ferramentas analíticas utilizadas na determinação de alterações bi oquímicas tra nsitó rás que, ao serem produzidas, geralmente: a) não resultam em transtornos funcionais; b) não provocam a ruptura da homeostase; c) não aumentam a su s cepti bilidade a outros agentes; d) e não incapacitam o organismo a compensar novas sobrecargas do elemento original.

Por princípio, os indicadores de efei to servem para avaliar as conseqüências e, indiretamente, a intensidade da exposição, ou seja, no momento em que os valores destas análises se distanciam dos valores estabelecidos como n ormais representam o desfecho de um processo de exposição.

$\mathrm{Na}$ maioria das vezes, quando analisados isoladamente, os indicadores de efeito fornecem poucas informações sobre o agen te tóxico. Con tu do, em determinadas situações em que o histórico de ex posição e o processo de trabalho são conhecidos - e em que o indicador apres enta um alto grau de especificidade -, os resultados permitem aferir a exposição a um ou mais agen tes, de s de que po s suam mecanismos semelhantes de interação com o meio biológico.

Dentre todos os métodos diagnósti cos acima apresentados, os indicadores de efei tos são os menos sensíveis. Entretan to devi do ao baixo custo (em relação aos demais métodos), e stes métodos são amplamen te utilizados, em particular nos países em desenvolvimento e, sobretudo, como indicadores de diagnóstico rápido da situação de saúde de uma determinada população, facilitando as estratégias de intervenção local e terapêutica individual.

Diversos indicadores de efei to, tais como a ativid ade da enzima $\mathrm{Na}^{++} / \mathrm{K}^{+}$ATPase e o tempo de coagulação sanguínea, têm sido utilizados sistematicamente para a avaliação da exposição a determinados tipos de agrotóxicos. Entretan to nenhum indicador de efeito, relacionado à exposição a agrotóxicos, tem sido mais 
utilizado que as colinesterases sanguíneas (Ol ivei ra-Silva et al., 2000).

As colinesterases sangüíneas são enzimas que atuam no organismo humano como mediadores químicos. Estas enzimas são inibidas na presença de agrotóxicos das classes dos organofosforados e dos carbamatos (por esta razão também conhecidos como "anticolinesterásicos”). Um indivíduo, uma vez exposto a agrotóxicos destas classes, tem sua atividade colinesterásica diminuída quantitativa e proporcionalmen te à intensidade da exposição, uma das razões pelas quais estes indicadores de efei to são amplamen te utilizados no mon i toramen to humano a estes agen tes agrotóxicos.

Embora apre s en tem sérias limitações qu a nto à ex a tidão de seus result ados - compa rativamen te aos indicadores de dose interna -, as colinesterases sangüíneas ainda se constituem importantes indicadores da ex posição humana a agrotóxicos, sobretudo nos países em desenvo lvimento como oBrasil, on de a ex tensão terri torial e a carência de laboratórios de referência - distribuídos pelo país -, capazes de atender as áreas ru rais e remotas, consti tu em sérios limitantes ao uso de metodologias baseadas em instru m entação analítica mais elaborad a. Além disso, observa-se também uma grave deficiência na formação dos agentes de saúde e médicos que atuam nestas populações - principalmen te no que diz respei to à iden tificação dínica de sintomas relacionados com a intoxicação por agrotóxicos. Assim, apesar da imprecisão in eren te a esta metodologia, o uso destes indicadores não deve ser sistematicamente abandonado como estratégia de monitoramento de populações ex postas a agrotóxicos anticolinesterásicos - principalmente na identificação de situações emergenciais - mas sim criteriosamen te utilizado, den tro de seus limites.

Alguns dos pontos críti cos da utilização das colinesterases sangüíneas como indicadores da exposição aos anticolinesterásicos se referem aos valores de referência utilizados e ao de s conhecimen to do com port a men to des tes indicadores qua n do inibi dos. A correção des tes pontos críticos, por parte do prof is s i onal avali ador, pode representar uma melhoria da exatidão dos resultados obtidos, diminuindo o peso dos fa tores de interferência.

Os valores de referência usualmente utili$\mathrm{z}$ ados são con s truídos através da determinação das atividades médias destas enzimas em populações não expostas. Deste valor médio deve-se subtrair de $25 \%$ a $30 \%$ da atividade mé- dia e então estabel ec i do o va l or de referência limite (pon to de corte). Abaixo de stelimite o indivíduo deve ser considerado exposto a uma con cen tração el evada de stes agen te s.

Ocorre que o pon to de corte tem duas origens distintas: uma clínica e outra estatística. A origem clínica reside no fato de não se observar qualquer sintomatologia até uma redução de cerca de $25 \%$ da ativid ade anteri or à ex po sição. Do pon to de vista estatísti co, considerando-se a atividade colinesterásica como ten do uma distri buição gaussiana normal, o valor de subtração corresponde ao desvio padrão de 1,645 da média que, de um modo geral, repres enta $30 \%$ da atividade média. É importante reforçar que este recurso só é válido quan do as atividades enzimáticas destes indicadores seguem uma distribuição normal. Em populações com menor e maior heterogen eidade, este val or de subtração varia.

Em estudo realizado pelo Laboratório de Toxicologia do Ces teh/Fiocruz com um gru po de 102 trabalhadores rurais (Oliveira-Silva et al., 2003), foi possível demonstrar que a adoção de um valor médio de uma população não exposta, subtraído de 30\% (VR30), produziu a proximadamente $28 \%$ de re sultados falsos negativos e $17 \%$ de falso positivos, totalizando $45 \%$ de re sult ados incorreto s.

Quandose adotou, na mesma amostra, um valor médio subtraído do desvio padrão de 1,6425 (VR1,6) como valordereferên cia, a proximadamen te $9 \%$ dos resultados foram falsos positivos e $18 \%$ de falsos negativos, totalizando $27 \%$ de resultados sem con s onância com a re alidade. Es te estudo só foi possível com a obtenção dos valores de referência do próprio indivíduo, que foi utilizado como padrão-ouro (Olivei ra-Silva et al., 2003). A adoção de s te critério analítico indica que aproximadamente $34 \%$ da população estudada estava exposta a anticolinesterásicos e não $20 \%$ como constatado inicialmen te.

O utro fator de interferência iden tificado na realização deste monitoramento é o chamado "efeito rebote" da colinesterase plasmática, a B ChE (butirilcolinesterase). Em estu dos anteriores (Oliveira-Silva et al., 2000; 2001), nos quais aproximadamen te 300 trabalhadores tiveram sua atividade colinesterásica mon i torada duran te um ano, ob servou-se que $\mathrm{BCh} \mathrm{E}$, no intervalo de 11 a 20 dias, a presentava um comportamento atípico, caracterizado por um aumento médio de suas atividades em torno de $14 \%$, sendo que em alguns casos atingia $42 \%$ 
da atividade basal, efei to este não ob s ervado na colinesterase das hemácias, a AChE (acetilcolinesterase). Tal efeito, relacionado ao processo de renovação sangüínea desta enzima plasmática, se apresenta como determinantede falsos resultados (tanto positivos quanto negativos), contribuindo para um diagnósti co impreciso da ex posição humana a agrotóxicos.

Como forma de corri gir tais distor çõ es, para o mon itoram en to oc u pacional re aliz adonaqu ela amostra de 102 trab al hadores (Ol ivei ra - Si lva et al., 2003), utilizou-se apenas a AChE. Tal fato não inviabiliza o uso da BChE, ou mesmo das colinesterases to tais, como nos kits de diagnóstico rápido - fundamentais ao atendimento de emergências, mas alerta para a possibilidadede os resultados produzidos a partir destes métodos estarem sub ou sobre-mensurados.

\section{Determinantes sociais, culturais e econômicos das intoxicações}

A utilização dos agrotóxicos no meio ru ral brasileiro tem trazido uma série de conseqüências tanto para o ambien te como para a saúde do trabalhador rural. Em geral, essas conseqüências são condicionadas por fatores intrinsecamen te relacionados, tais como o uso inadequ ado dessas substâncias, a pressão exercida pela in dús tria o comércio para esta utilização, a alta toxicidade de certos produtos, a ausência de informações sobre saúde e segurança de fácil a propriação por parte de ste gru po de trabalhadores e a precariedade dos mecanismos de vigilância. Esse quadro é agravado por uma série de determinantes de ordens cultural, social e econômica.

Um trabalho realizado no município de Magé (RJ) avaliou a relação entre a exposição de 300 agricultores a agrotóxicos e suas relações com uma série de determinantes socioeconômicos (Oliveira-Silva et al., 2001). Estes trabalhadores tiveram seu sangue analisado, para a determinação do grau de exposição/intoxicação, a través da do sa gem da atividade colinesterásica. Dados socioecon ô mi cos e de utilização de agrotóxicos, para cada trabalhador, foram obti dos em en trevista estrutu rada.

O possíved papel dos indicadores soci oeconômicos e de uso de agrotóxicos sobre o nível de contaminação dos trabalhadores foi estimado por análise de regressão linear múltipla, utilizando-se a atividade enzimática como variável depen den te e os indicadores soci oecon ô mi- cos e de uso de agrotóxicos como variáveis independentes.

Os resultados daquele estudo mostraram um perfil da ex posição a estes com po s tos na região, onde aproximadamente $44 \%$ da amostra apresentava redução significativa da atividade colinesterásica. Estes dados foram confrontados com os indicadores socioeconômicos e de utilização de agrotóxicos, ten do se destacado a importância do nível de escolaridade sobre a prevalência das intoxicações.

Aproximadamen te $70 \%$ da amostra apresentava mínima ou nen huma habilidade de leitu ra e escrita. Esta va ri á vel era fortemente correlacionada com a atividade colinesterásica $(\mathrm{r}=$ 0,646 e $\left.\mathrm{r}^{2}=0,418\right)$, indicandoa influência destes fatores no processo que determina a ex po $\mathrm{s} i$ ção/contaminação dos trabalhadores aos agrotóxicos. Para os demais determinantes estudados (idade, uso de EPI, etc.), n en huma correl ação significativa foi tão evidente.

A interpretação destes resultados fica mais dara quando levados em con sideração dois outros fatores que atuam de forma determinante no processo que resulta na exposição dos trabalhadores rurais a agrotóxicos: o processo de comunicação que tem como obj etos os saberes rel acionados ao manejo de agrotóxicos; e a percepção de riscos daqueles que utilizam estes agentes químicos em seu processo de trabalho.

No meio rural brasilei ro, como um todo, observa-se um elevado índice de analfabetismo e baixa escolarid ade (IBGE, 2000; Ol iveira-Silva, 1994), fato este que determina uma série de políticas de comunicação visual (como o uso de ilustrações, figuras, pictogramas, faixas coloridas, etc.) em produtos e informes direcionados a esta audiência. Essas figuras, em especial os pictogramas (representações gráficas de rápida visualização, como a "c aveirinha" que indica peri go, ou o "par de luva s" que indica a obriga toriedade do uso de luvas no manuseio de tal produto), são en con tradas em rótulos de produtos agrotóxicos, em teoria para informar à qu elas pessoas que não dispõem de habilidade de leitura/escrita.

Os resultados de um estudo de recepção de informações realizado em uma região agrícola do Estado do Rio de Jan eiro (Peres, 1999; Peres et al., 2001), en tret an to, mostraram que os trabalhadores não conseguem iden tificar as informações presen tes nos pictogramas e em figuras, de uma forma geral, devi do à falta de clareza ("po luição visual") dessas figuras/pictogramas. O utro dado do estu do de recepção está di- 
retamente rel acion ado ao uso de linguagem rebuscada (portanto de difícil apropriação por parte desta audiência específica) em materiais in form a tivos e rótulos/bulas de agrotóxicos.

Durante a pesquisa, foi apre s en tada aos trabalhadores entrevistados a seguinte frase, retirada do rótulo do herbicida Gramoxone ${ }^{\circledR}$, o produto mais utilizado na região - e um dos mais utilizados em toda a área rural do país: Esta fo rmulação contém um agen te emético, po rtanto não controle vômito em pacientes recém in toxicados por via oral, até que pela ação do esvaziamen to gástri co do herbicida, o líquido estomacal venha a ser claro.

Tal informação é de fundamental importância, vi s to que o produto apre s enta coloração amarronzada, semelhante a dos refrigerantes tipo cola, o que faz com que tal produto seja freqüentem en te confundido com estes refrigera $n$ tes por crianças que, in advertidamente, ac abam ingerindo este produto altamente tóxico. Aproximadamen te $40 \%$ dos trabalhadores entrevis tados $(n=23)$ en ten deram que não se deveria deixar a pessoa intoxicada vomitar para que o veneno saísse do organismo (no caso, a dupla negativa "não con trole" era identificada como "não provoqu e", i nverten do o sen ti do da frase), o utros $40 \%$ não faziam a men or idéia do que tal frase informava e $20 \%$ interpretaram que era um veneno "brabo", e que se a pessoa bebesse, morreria (Peres, 1999). Um trabalhador perguntou ao entrevistador qual seria o significado daquela frase. Ao receber a devida explicação, em uma linguagem apropriada, sobre significado da frase, es te trabalhador su geriu uma interessante construção: Em vez disso aí, o sujei to não podia escrever "se o caboclo beber o veneno, deixe ele vomitar até as tripa”! (Agricultor, 35 anos)

Deve-se crer que sim...

O utro aspecto levantado pelo estu do tinha relação com a percepção das cores dos rótulos de embalagens de agrotóxicos (faixas que indicam a classe toxicológica dos produtos). O trabalhador rural, de uma maneira geral, tende a con s truir suas percepções e pensam en to a partir de elemen tos concretos (fatos vivi dos e experimentados) de seu dia-a-dia, apresentando dificuldades na interpretação de situações abstratas (como exemplos hipotéticos, correl ações mais amplas, etc. - Rozem berg \& Peres, 2003).

Baseado nessas percepções, alguns trabalhadores rurais entrevistados correlacionaram as faixas coloridas dos rótulos de agrotóxicos com os sinais de trânsita Para eles, o produto com faixa vermelha é muito perigoso, logo a pessoa tem de "parar" a n tes de usá-lo (analogia com o sinal vermelho); o produto com faixa amarela é merecedor de "atenção" (analogia com o sinal amarel o ); e o produto com faixa verde é "liberado para ser usado à vontade" (analogia com o sinal verde), o que pode repre s entar um sério risco à saúde desses trabalhadores, pois embora os produtos de tarja verde - classe toxicológica IV - sejam pouco tóxicos, eles podem, em quantidades demasiadas, provocar uma série de efeitos nocivos à saúde do traba1 h ador, in clu sivelevá-lo à morte (Peres, 1999).

A experiência dos trabalhos aqui apresentados mostrou que os trabalhadores ru rais são, como amplamen te difundido, carentes de informações. En tret a n to, não são, e jamais devem ser vis tos como caren tes de cultura. Mui to pelo con trário; na realidade, a cultu ra do hom em do campo é riquíssima, embora seja construída em uma sintaxe estranha à "cultura técnica/acad êmica”, o que, muitas vezes, acaba por prom over a manutenção de um distanciamen to e hierarquização na relação entre técnicos e trabalhadores rurais, facilitando assim, a imposição da visão de mundo desses profissionais "sobre" sua "di en tela" (Peres, 1999; Ugalde, 1985). O grande desafio que se configura é, portanto, in corporar essa cultura nas informações direcionadas a este grupo populacional. Ou seja, construir a informação em uma sintaxe comum aos dois grupos (técnicos e trabalhadores rurais).

\section{O discurso determinista da indústria e a legi timação do uso de agrotóxicos}

Olhando para o atual panorama do consumo de agrotóxicos no país e no mundo, algumas perguntas ainda permanecem sem respostas con clu s ivas: s erá que não ex i s tem mesmo alterna tivas a estes produtos? Será que a população se tornou, para sempre, refém dos agrotóxicos? Será que cen tenas de anos gastos com o aprimoramento de técnicas orgânicas de controle de pragas devem ser, simplesmente, jogados ao acaso de suas existências?

A questão cen tral não parece estar relacionada à existência ou não de técnicas alternativas ao uso de agrotóxicos, e sim ao caráter determinista do discurso industrial, que permeia diversos setores da sociedade e acaba por ser consolidado (por impregnação) nas falas de trabalhadores rurais, os interlocutores mais distantes e distanciados neste processo de co- 
municação. E tal fato fica bastante explícito quando se analisam alguns dados, como os que serão apres en tados a seguir.

Segun do dados da FAO (2003), o mercado mundial de agrotóxicos movimentou, somente no ano de 2000, cerca de 22 bilhões de dólares em todo o mundo. No Brasil, o comércio destes produtos é estimado pelo Sindag (2001) em cerca de 2,5 bilhões de dólares, o que coloca o país no sétimo lu gar do ranking dos países consumidores de agrotóxicos (Anvisa, 2002).

Visualizando estes dados, torna-se cla ro o discurso ora vigen te no país da impossibilidade da produção agrícola sem o uso de agrotóxicos. Os defensores de ste discurso, grupo que in clui não apenas técnicos ligados às indústrias e ao comércio destes produtos, como também profissionais do poder público, desconsideram as técnicas alternativas ao uso de agrotóxicos, por ac reditar no modelo agrícola da monocultura ex port adora, sustent ado pelo uso abu sivo de agrotóxicos e outros insumos químicos, e que vem sendo o fiel da balança com ercial brasileira nos últimos anos. A uniformidade e as semelhanças entre o discurso destes profissionais e o das grandes indústrias são assustadoras: pou cos produzem alimen tos para muitos e, caso não se ga ranta uma alta produtividade, com o (ab)uso de agrotóxicos na lavoura, não $\mathrm{h}$ averá alimen to para saciar a fome de uma população que cre sce incessantem ente.

Entretanto, a realidade é outra: de acordo com a própria FAO (2003), foram produzidas em 2001 aproxim ad a m en te nove trilhões de toneladas de produtos agrícolas, provenien tes de lavouras primárias (sem beneficiamento). Pode-se considerar, minimamente, que apenas $5 \%$ deste montante é destinado ao consumo direto (contabilizando as perdas com estocagem e o montante que vai para o beneficiamen to e para a en gorda animal); s obram aproximadamen te 450 milhões de toneladas/ano para alimentar uma população de pou co mais de seis bilhões de pessoas, o que resultaria em algo como $200 \mathrm{~kg}$ de alimen to disponível por habitante por dia. Tomando que, em média, são necessários $2 \mathrm{~kg}$ de alimentos não processados/dia para alimentar uma pessoa, teria-se h oje uma produtividade capaz de alimentar 100 planetas somen te com lavouras primárias (sem contar os produtos ben eficiados e os de ori gem animal).

A perda média de produtividade com as técnicas altern a tivas de controle de pra gas mais consagradas chega à casa de 60\% (existem ex- periências bem - su cedidas em que a perda é de aproximadamente $10 \%)$. Ainda assim, h averia hoje a capacid ade de alimentar 40 planetas sem o uso de agrotóxicos.

A produtividade agrícola atual é suficiente para suprir as demandas mundiais de alimento. Não falta comida: falta coragem às pessoas para admitir que o que impulsiona o modelo agrícola atual, baseado no uso intensivo de agentes químicos, não é a ga ran tia da demanda alimentar do planeta, e sim a garantia dos luc ros relacion ados à produção agrícola mundial e à produção/comercialização de agrotóxicos. A fome não é, como dizem os "doutores" dos agrotóxicos, um problema de produção, e sim um problema de distri buição de riquezas.

Por outro lado, as técnicas de controle de pragas alternativas aos agrotóxicos são, hoje, uma realidade, tan to em termos da produtividade quanto em relação aos custos, além de apresentarem um potencial de contaminação humana ou ambiental muito menor, ou mesmo desprezível.

O controle dos probl emas relacionados ao uso indiscriminado e descuidado dos agrotóxicos, já iden tificados e bem conheci dos pela comunidade científica em geral, som en te poderá ser alcançado com a adoção de práticas alterna tivas ou, qu a n do estrita men tenecessário, pelo uso seguro, criterioso e cuidadoso destas substâncias. Para tal, governo, socied ade or ganizada, gru pos de interesse e organizações não governamentais devem estar unidos por um obj etivo maior que olucro: a ga ra n tia da qualidade de vida do trabalhador rural, do ambiente edapopulação, consumidora dos produtos provenientes da lavo ura. Enquan to este problema não for considerado uma prioridade de governo, a situação ten de a se agravar e se expandir cada vez mais, ameaçando até mesmo os grandes centros urbanos, adjacentes a áreas de cultivo, cujas fron teiras estão cada vez mais próximas.

\section{A não incorporação da percepção de riscos das comunidades na construção de estratégias educativas}

De uma manei ra geral, podemos con ceber que uma gran de parcela da população está exposta aos efei tos nocivos de produtos agrotóxicos. A contaminação (ou não) destas pessoas, muito provavel $m$ ente, está rel acionada não apenas ao grupo ao qual perten cem, mas também à maneira com o, in divi dual ou coletivamente, estas 
pessoas iden tificam e se posicionam diante dos ri scos a que estão expostas. Ocon hecimen to da percepção de riscos destes indivíduos ou grupos populacionais específicos é, portanto, fundamental para a construção de estratégias de intervenção sobre o probl ema (Peres, 2003b).

A con strução - indivi dual ou coletiva - da percepção de riscos é resultante direta do conhecimento sobre o assun to em questão que, por sua ve $\mathrm{z}$, écon stituí do a partir das repre s entações e interpretações das informações disponíveis.

Os estudos de percepção de ris cos surgem no final da década de 1970-1980, como importante con trapon to à perspectiva utilitarista da análise e gerenciamento de riscos, com o objetivo de incorporar determinadas escolhas sociais, políticas e econômicas em problemas "puram en te" técnicos e científicos (Gomez \& Freitas, 1997). Naquele momen to, tornava-se urgen te a consolidação de estratégias de análise de risco que levassem em consideração a percepção (no sen ti do mais amplo da palavra) dos indivíduos, comunidades e grupos populacionais envo lvidos com os proce s s o $\mathrm{s} / \mathrm{si}$ tuações potencialmentedanosos.

Em estudos sobre a percepção de ris cos de comunidades agrícolas expostas a agrotóxicos em duas localidades do Estado do Rio de Ja neiro (Peres, 2003a), foi possível observar que a maioria dos entrevist ados $(n=60)$ percebia algum peri go nas prá ticas de uso destas substâncias (apenas um entrevistado não identificou peri go qualquer). No total, $90 \%$ dos trabalhadores, quan do perguntados sobre os agrotóxicos (de uma manei ra genérica), responderam "perigoso", "muito perigoso", "um perigo", ou "um troço mu i to ruim".

Os principais sinais/sintomas relatados como "problemas de saúde relacionados aos agrotóxico s" eram dores de cabeça, dores de barriga e ton teiras. Tais sinais são obs ervados mais freqü en temen te em episódios de intoxicação aguda, cujo quadro sintomatológico é bastante forte - convulsões, desmaios, etc. - o que vem reforçar a importância da ob s ervação de fatos cotidianos na construção do pensamento do homem do campo.

A "invisibilidade" dos riscos relacionados ao uso de agrotóxicos acaba por determinar uma maior exposição a estes produtos, por parte dos trabalhadores rurais, assim como con tribui p a ra a degradação do ambiente, como se ob s erva na frase a seguir, registrada duran te a realização daquele estudo (Peres, 2003a): Eu num a cho que prejudica nada. (...) você pu lverizou lá um gra moxone lá dentro do inhame. Diz que se dê uma ch uva leva lá pra den tro do rio. Leva nada! Até chegar lá já acabou o efeito. Eu acho que já acabou o efei to. Eu quanto a isso eu acho que num tem nada prejudicando o meio ambien tede água, essas coisas assim. Eu pen so que não (Agricultor, 72 anos).

No que se refere à or ganização do trabalho rural, convém ressaltar a existência de uma divisão das tarefas de acordo com o sexo: as mulheres participam ativamen te das principais etapas do trabalho agrícola, e assumem todo o trabalho doméstico. Em uma primeira análise poderia se pensar que as mulheres não estão tão expostas aos agrotóxicos quantos os homens, já que, geralmente, o processo de pulverização é uma tarefa masculina. En tretanto, mesmo durante este processo, as mulh eres ajudam os seus maridos, puxando as mangueiras - no caso de pulverizadores mecânicos - ou abastecen do os pulveriz adores costais (manuais). Pelo fato de o mari do estar no comando do pulverizador (e, muitas vezes, usando algum ti po de equipamento de proteção), as mulheres não percebem os ris cos a que estão ex postas (e, freqüen temente, encon tram-se sem qualqu er equ ipamen to de pro teção individual). Es te fato caracteriza a situação de ri sco ex perimentada pelas mulh eres em todo o meio rural brasileiro, e aponta para a necessid adede estu dos mais a profund ados sobre a relação da mulher no proce sso de trabalho ru ral que envo lve a utilização de agrotóxicos (Peres et al., 2004). Ademais, suscita a necessidade de estratégias educativas e de comunicação de ris cos foc adas neste grupo.

Estudos de percepção de riscos não devem estar dissoci iados de esforços educativos, de políticas e estratégias que tenham como obj eto a promoção de transformações sociais nos grupos focalizados, razão pela qual estes estudos aparecem, cada vez mais, como subsídios a projetos e ações, sobretudo para o delineamen to de políticas e estrat égias que envo lvam práticas de comunicação de ris cos e campanhas educativas (Peres, 2002).

Aqui se observa um dado que acaba também por se caracterizar como importante determinante da situação ora apresentada: na tenta tiva de suprir as supostas carências cognitivas do hom em do campo, diversos profissionais edu cadores, sobretudo, - acabam de s consideran do os saberes e os conhecimen tos de stepersonagem e impondo seus valores de modernização das práticas rurais, uma vez que, para es- 
tes profissionais, e s teéo pon to estratégico para a superação de um impedimen to fundamental às melhorias de saúde nos países em desenvo lvimen to (Ugalde, 1985).

Tal postura, notadamente equivocada, repre s enta uma negação dos saberes de s te grupo, legi tim andovalores ex ternos e interessesalh eios aos dos habitantes das zonas rurais, contribuindo para a manutenção de uma posição sectá ria e exclu dente, que identifica o homem do campo como um ser "carente por natureza", que necessita ser alimentado, tratado, cuidado (Calazans et al., 1985). Pa ra Paulo Frei re, o profissional, por vezes, ten de a se esquecer ou minimizar o papel do hom em do campo em função de seu com promisso prof i s s i onal- baseado em ações de caráter técnico -, i m pon do sua visão de mundo a este grupo, sem o cuidado de invadir a cultura daquela audiência: Quase sempre, técnicos de boa vontade, embora ingênuos, deixam-selevar pela tentação tecnicista (mitificação da técnica) e, em nome do que chamam de "necessidade de não perder tempo", tentam, verticalmente, substituir os procedimen tos empiricos do povo por suas técnicas (Freire, 1997).

De acordo com Rozemberg \& Peres (2003), alguns profissionais, por desprep a ro, confundem, ainda, a habilidade para a leitura e o domínio da linguagem formal como critérios de julga men to sobre a inteligência e a capacidade de construção de raciocínios lógi cos da população rural. A saída para tal situação é sugerida pelos autores: Para desconstruir os preconceitos ainda tão freqüentes nas pu blicações e ações educativas, tais como os de que a população rural sem escol a ridade sof re de "falta de compreensão", "ignorância” ou "incongruência” é preciso que o profissional se acostume a problematizar de maneira crítica e aberta sua relação com valores e decisões tomadas em contextos sociais e culturais mu i to diferen tes do dele. Mas para tanto é nece ssário conhecer tais contextos, experiências, interesses, valores, racionalidades dos grupos com os quais deseja trabalhar. Pa ra isso a realização de pe squisas por parte do educador torma-seimprescindivel. Nossa experiência trabalhando com agriculto res nos últimos anos vem permitindo demonstrar, através de inúmeros exemplos de campo, que há uma lógica e uma racionalidade articulando a aparente "falta de sentido" de alguns disc u rsos. Essa lógica costuma estar ind usive, muito bem ancorada na visão de mundo dos grupos, ainda pouco con hecidos e compreendidos em sua própriaracionalidade ( Rozemberg \& Peres, 2003).

\section{Considerações finais}

Olhar para a situação ora vigen te no meio rural brasileiro, no que diz re spei to ao uso indiscriminado de agrotóxicos, não é uma tarefa simples. Não é o bastante conhecer as formas através das quais as populações humanas continuam, a cada ano, a se ex por e se contaminar por estes agentes. Avaliar o problema através do modelo clássico-toxicológi co que inclui a identificação do peri go, caracterização do risco, avaliação dose-resposta e gerenciamen to dos riscos, é insuficiente diante da dimensão desta situação que, ano a ano, acom ete milhões de pessoas em todo o mundo. Olhar para a questão sem o cuidado de ob servar os mais disc retos aspectos, tanto rel acion ados à forma como as populações humanas agem diante da necessidade de uso destes agentes químicos, quanto às limitações dos instrumen tos analíticos hoje disponíveis, é como olhar para uma figura distante: delimita-se, imprecisamente, o con torno, sem conhecer os detalhes que lhe dão a forma.

O objeto da contaminação humana e ambiental por agrotóxicos é, em sua natureza, complexo, e demanda um entendimento mais amplo do problema, dissociado da corren te que acredita (ou leva as pessoas a crer) que o problema é resultante da ignorância do homem do campo - que deliberadamen te se exporia aos ri s cos oriundos do processo de trabalho (visão esta que só interessa à indústria produtora destes agentes que, anualmente, fatura em cima de um merc ado estimado na casa dos bilhões de dólares).

Diversos aspectos, como a influência dos determinantes socioeconômicos, as dificuldades relacionadas à organização dos dados de intoxicação no país, os desafios metodológicos relativos ao monitoramento da exposição humana aos agrotóxicos e o reforço de estere ó tipos etnocêntricos do homem do campo, por parte de técnicos e educadores, trazem à discussão a necessidade de uma abord a gem interdisciplinar e integrada do probl em a, sem a qual exis te o risco de serem empreen didos esforços em vão, on erando desnecessariam en te tanto os órgãos de assistência rural quan to o Sistema Único de Saúde, responsáveis diretos pelo a tendimen to destas populações.

Vale, ainda, ser destac ada a forte influência de gru pos de interesse (no caso específico a indústria química e o comércio à qual está ligado) em criar as su postas "necessidades" que le- 
vam à adoção em massa de tais tec nologias. Somen te com a desvinculação dos interesses comerciais é possível reverter a situação ora ex perimen $\mathrm{t}$ ada pelos milhões de trabalhadores oc $\mathrm{u}$ pados no campo. Para tal, govern o, sociedade organizada, gru pos de interesse e organizações não governamentais devem estar unidos em torno de um objetivo maior que o lucro: a garantia daqualidade de vida do trabalhador rural, do ambiente e da população - con su mido- ra dos produtos provenien tes da lavo ura - como um todo.

E para tanto, abordagens integradoras e interdisciplinares devem ser ado tadas para a avaliação e o controle dos efeitos nocivos dos agrotóxicos sobre a saúde humana e o ambi en te, integrando as ciências farmacêuticas/toxicológicas e socia is / humanas de forma a co l ocar a vulnerabilidade das populações rurais e do ambi en te no eixo cen tral das análises e avaliações.

\section{Colaboradores}

F Peres e JJ Ol ivei ra-Silva participaram do levantamento dos dados de campo, da redação e da revisão do manu scri to. HV Della-Rosa e SR Lu cca partici p a ramda redação do manu scrito.

\section{Referências bibliográficas}

Anvisa 2002. Programa de Análise deResíduos de Agrotóxicos em Alimentos. Relatório Anual 4/06/2001 - 30/ 06/2002. Agência Nacional de Vigilância Sanitária, Brasília.

Biziuk M, Przyjazny A, Czerwinski J \& Wiergowski M 1996. Occurren ce and determinati on of pesticides in natural and treated waters. Am Journal of Chrom a to graphy 754:103-123.

Calazans MJC, Cas tro LFM \& Si lva HRS 1985. Questões e contradições da educação rural no Brasil, pp. 1315. In J Werth ein \& JDE Borden ave (orgs.). Educação ru ral no Tercei ro Mundo: experiências e novas alternativas. Paz e Terra, Rio de Janei ro.

Frei re P 1997. Educação e mudança. Rio de Ja nei ro, Paz e Terra, Rio de Janei ro.

Garri do EM, Lima JL \& Del erue-Ma tos C 2003. Electroch emical and Spect ro s copic Studies of the Oxid a ti on Mechanism of the Herbicide Propanil. J Agric Food Chem 51(4):876-879.

Gomez CM \& Freitas CM 1997. Análise de riscos tecnológi cos na perspectiva das ciências sociais. História, Ciên cia e Saúde-Manguinhos 3(3):485-504.

IBGE 2000. Censo Demográfico. Rio de Janeiro, Editora do IBGE, Rio de Jan ei ro.

Jeyara tnam J 1990. Acute pesticide poisoning: a major global health problem. World Health Stat Quaterly 43(3):139-144. 
Larini L 1999. Toxicologia dos praguicidas. Manole, São Paulo.

Levi en RS \& Doull J 1993. Global estimates of ac ute pe sticide morbidity and mortality. Reviews of Environmental Contamination and Toxicology 129:29-44.

Morei ra JC, Jacob SC, Peres F, Lima JS, Meyer A, Ol ivei raSilva JJ et al. 2002. Avaliação integrada do impacto do uso de agrotóxicos sobre a saúde humana em uma comunidade agrícola de Nova Friburgo/RJ. Ciê $n$ cia e Saúde Coletiva 7(2):299-311.

Mukherjee I \& Gopal M 1996. Ch romatographic techniques in the analysis of organochlorine pesticide residues. Am Journal of Chromato graphy 754:33-42.

Ol ivei ra-Silva JJ 1994. Enzimas como indicadores biológicos da exposição a pesticidas organofosforados: um estudo realizado com trabalhadores rurais no município de Magé - RJ; as bases para um programa de monitoramento ocupacional. Dissertação de mestrado. Escola Nacional de Saúde Pública, Rio de Jan eiro.

Ol iveira-Silva JJ, Alves SR \& Inacio AF 2000. Cholinesteraseactivities determination in frozen blood samples: an improviment to the occupati onal monitoring in devel oping countries. Human \& Experimental Toxicology 19:173-177.

Ol ivei ra - Si lva JJ, Alves SR, Meyer A, Peres F, Ma tos RCO, Sarcin elli PN et al. 2001. Influência de fatores socioeconômicos na contaminação por agrotóxicos, Brasil. Revista Saúde Pública 35(2):130-135.

Ol ivei ra Si lva JJ, Alves SR \& Della Rosa HV 2003. Avaliação da ex posição humana a agrotóxicos, pp. 121-136. In F Peres \& JC Morei ra (orgs.). É veneno ou é remédio? Agrotóxicos, saúde e ambiente. Fiocruz, Rio de Janeiro.

Peres F 1999. É ven eno ou é remédio? Os desafios da co municação ru ral sobre agrotóxicos. Dissertação de mestrado. Escola Nacional de Saúde Pública, Rio de Jan eiro.

Peres F 2002. Onde mora o peri go? Percepção de riscos, ambiente e saúde, pp. 135-141. In MCS Minayo \& AC Mi randa (orgs.). Saúde e ambi ente sustentável: estreitando nós. Fiocruz, Rio de Ja neiro.

Peres F 2003a. Onde mora o perigo? O processo de desenvolvimen to de uma metodologia de diagn ós ti co rápido da percepção de risco no trabalho rural. Tese de do utorado. Unicamp, Campinas.
Peres F 2003b. Os desafios da con s trução de uma abord agem metodológica de diagnóstico rápido da percepção de risco no trabalho, pp. 251-282. In F Peres \& JC Moreira (orgs.). É ven eno ou é remédio? Agrotóxicos, saúde e ambi en te. Fiocruz, Rio de Ja n ei ro.

Peres F, Rozemberg B, Alves SR, Morei ra JC \& Ol iveiraSilva JJ 2001. Comunicação relacionada ao uso de agrotóxicos em uma região agrícola do Estado do Rio de Ja n ei ro. Rev. Saúde Pública35(6):564-570.

Peres F, Lucca SR, Pon te LMD, Rodrigues KM \& Rozemberg B 2004. Percepção das condições de trabalho em uma tradicional comunidade agrícola em Boa Esperança, Nova Friburgo, Rio de Janei ro, Brasil. Cad. Saúde Pública 20(4):1059-1068.

Rozem berg B \& Peres F 2003. Reflexões sobre a edu cação relacion ada aos agrotóxicos em comunidades rurais, pp. 367-384. In F Peres \& JC Moreira (orgs.). É veneno ou é remédio? Agrotóxicos, saúde e ambiente. Fiocruz, Rio de Janei ro.

Samped ro MC, Gomez-Ba lu gera Z, Goi colea A \& Barrio RJ 1998. Determinati on of the insectici depyridafenthion in river water, soils and wine by adsorptive stripping voltammetry. Food Addit Contam. 15(7):793800.

Sindag (Sindicato Nacional da Indústria de Produtos para a Defesa Agrícola) 2001. Informações ao setor. Disponível em <http://www.sindag.com.br/new/setor/index.php $>$. Ace s s ado em 15/09/2001.

Si ni tox (Si s tema Naci onal de In formações Tóxico - fa rmacológicas) 2003. Casos registrados de intoxicação e/ou enven en a men to. Disponível em <www.fiocruz. $\mathrm{br} /$ sinitox $/ 2002 /$ brasil2002.htm $>$. Ace s sado em 4/12/ 2003.

Tu rdean GL, Popescu IC, Oniciu L \& Th evenot DR 2002. Sensitive detection of organophosphorus pesticides using a needle type amperometric acetylcholinesterase-based bi oel ectrode. Thiocholine el ectroch emistry and immobilised enzyme inhibition. J Enzyme Inhib Med Chem. 17(2):107-115.

Ugalde A 1985. Ideological dimensions of community participation in Latin Am erica health programs. Social Scien ces and Med icine 21(1):41-53.

Artigo apresentado em 3/12/2004

Aprovado em 1@/03/2005

Versão final apresentada em 10/03/2005 